\title{
“DEPRIVATIZATION OF PRACTICE" COMO ESTRATÉGICA DE FORMAÇÃO INICIAL DOCENTE NO PIBID PEDAGOGIA
}

\author{
“DEPRIVATIZATION OF PRACTICE" COMO POSIBILIDAD ESTRATÉGICA DE \\ FORMACIÓN INICIAL DOCENTE EN EL PIBID PEDAGOGÍA
}

\author{
“DEPRIVATIZATION OF PRACTICE” AS A STRATEGIC OF INITIAL TEACHER \\ TRAINING IN PIBID EDUCATION
}

\author{
Talita da Silva CAMPELO ${ }^{1}$ \\ Giseli Barreto da CRUZ ${ }^{2}$
}

\begin{abstract}
RESUMO: O artigo decorre de um estudo sobre como se constrói a aprendizagem da docência no contexto do Programa Institucional de Bolsas de Iniciação à Docência (PIBID), proposto pela CAPES. Metodologicamente, trabalhou-se centralmente com um questionário exploratório submetido aos licenciandos bolsistas do PIBID Pedagogia de nove subprojetos vinculados a cinco universidades públicas situadas no estado do Rio de Janeiro que desenvolvem suas ações nos anos iniciais do Ensino Fundamental regular. Os dados, construídos e analisados teoricamente com base em Cochran-Smith, se aproximam de aspectos que se assemelham ao que a autora caracteriza como "deprivatization of practice" em subprojetos de duas instituições. Com intuito de explorar melhor este conceito e compartilhar parte do que o GEPED - Grupo de Estudos e Pesquisas em Didática e Formação de Professores vem desenvolvendo segundo as contribuições de Cochran-Smith, o artigo apresenta, a partir da análise de dados empíricos, descritores de processos que podem contribuir para a formação de professores.
\end{abstract}

PALAVRAS-CHAVE: Formação de professores. Deprivatization of practice. PIBID.

RESUMEN: El artículo se deriva de un estudio sobre cómo se construye el aprendizaje de la docencia en el contexto del Programa Institucional de Becas de Iniciación a la Docencia (PIBID) propuesto por la CAPES. Metodológicamente, se trabajó centralmente con un cuestionario exploratorio sometido a los licenciantes bursátiles del PIBID Pedagogía de nueve subproyectos vinculados a cinco universidades públicas situadas en el estado de Rio de Janeiro que desarrollan sus acciones en los años iniciales de la Enseñanza Fundamental regular. Los datos, construidos y analizados teóricamente basados en Cochran-Smith, se aproximan a aspectos que se asemejan a lo que la autora caracteriza como "deprivatization of practice" en subproyectos de dos instituciones. Con el fin de explorar mejor este concepto y compartir parte de lo que el GEPED - Grupo de Estudios e Investigaciones en Didáctica y Formación de Profesores viene desarrollando según las contribuciones de Cochran-Smith, el artículo presenta, a partir del análisis de datos empíricos, descriptores de datos procesos que pueden contribuir a la formación de profesores.

${ }^{1}$ Universidade Federal do rio de Janeiro (UFRJ), Rio de Janeiro - RJ - Brasil. Doutoranda da Faculdade de Educação. ORCID <http://orcid.org/0000-0002-8994-4109>. E-mail: talitacampelo@ gmail.com

${ }^{2}$ Universidade Federal do rio de Janeiro (UFRJ), Rio de Janeiro - RJ - Brasil. Professora Adjunta da Faculdade de Educação. ORCID <https://orcid.org/0000-0001-5581-427X>. E-mail: cruz.giseli@gmail.com 
PALABRAS CLAVE: Formación de profesores. Deprivatization of practice. PIBID.

ABSTRACT: The article stems from a study on how to build teaching learning in the context Scholarship Programs for Teaching (PIBID) proposed by CAPES. Methodologically, we worked centrally with an exploratory questionnaire submitted to the new teachers (undergraduate fellows) of nine subprojects linked to five public universities located in the state of Rio de Janeiro that develop their actions in the initial years of Regular Elementary Education. The data, constructed and analyzed theoretically based on Cochran-Smith, approach aspects that resemble what the author characterizes as "deprivatization of practice" subprojects of two institutions. In order to better explore this concept and share part of what the GEPED - Group of Studies and Research in Teaching and Teacher Training has been developing according to the contributions of Cochran-Smith, the article presents, from the analysis of empirical data, descriptors of processes that can contribute to teacher training.

KEYWORDS: Teacher training. Deprivatization of practice. PIBID.

\section{Introdução}

Este artigo apresenta resultados de um estudo que buscou investigar como se desenvolve a aprendizagem da docência no contexto do Programa Institucional de Bolsas de Iniciação à Docência (PIBID). Quais as principais ações que permeiam o PIBID? Quais percepções sobre tais ações deixam ver licenciandos bolsistas participantes do programa? Como o trabalho desenvolvido no programa tem contribuído para a formação e atuação docente? Centrados nos subprojetos de Pedagogia vinculados a cinco universidades públicas localizadas no estado do Rio de Janeiro, que desenvolvem suas ações exclusivamente junto a turmas dos anos iniciais do Ensino Fundamental regular, foi possível identificar em dois deles aspectos que se assemelham ao que Cochran-Smith (2012) caracteriza como "deprivatization of practice"3. É com foco nesse conceito que este trabalho se desenvolverá.

Integrante do Plano Nacional de Formação de Professores (BRASIL, 2009), o PIBID é um programa brasileiro de iniciação à docência, caracterizado pela CAPES como uma iniciativa para o aperfeiçoamento e a valorização da formação de professores para a educação básica. O lançamento do programa se deu em dezembro de 2007, mediante Edital MEC/CAPES/FNDE 01/2007.

O PIBID visa à participação de licenciandos em atividades de ensino-aprendizagem no contexto da escola pública. O programa é desenvolvido por meio da concessão de bolsas de

\footnotetext{
${ }^{3}$ Optou-se por usar o termo em inglês devido a não identificação de um termo correspondente em português que
} não comprometesse o sentido original. 
iniciação à docência para estudantes, bolsas de coordenação para professores coordenadores (Instituições de Ensino Superior) e bolsas de supervisão para professores supervisores (Escola Básica). Além da concessão de bolsas, dois aspectos situam-se no nosso entender como diferenciais: a oportunidade de pensar e fazer a docência com professores da escola básica em contexto real de trabalho; e a imersão dos licenciandos na escola com marcações mais amplas de tempo.

O PIBID possibilita que os licenciandos experimentem a docência através do planejamento e desenvolvimento coletivo - licenciandos, professores da escola básica (supervisores) e professores da universidade (coordenadores) - de atividades de aula, de construção de materiais didáticos e de criação de projetos interdisciplinares, sempre abertos à crítica do grupo.

Acreditamos que privilegiar na formação de professores a imersão na prática pressupõe a criação de situações em que professores em formação inicial e professores experientes possam pensar, investigar, refletir e trocar saberes sobre o que os constitui como docentes: seu trabalho. Não se trata, portanto, de meramente aumentar o tempo dos licenciandos na escola, mas de qualificar este tempo, privilegiar outros protagonismos, criar novos cenários, proporcionar outros tipos de experiência e convivência. Nota-se isso no processo de "deprivatization of practice".

$\mathrm{O}$ termo "deprivatization of practice" é cunhado por Marilyn Cochran-Smith ${ }^{4}$ no contexto de estudos sobre comunidades de prática. Para Cochran-Smith e Lytle (1993; 1999; 2009), o propósito essencial dessas comunidades é cultivar a aprendizagem da docência ao longo da vida e possibilitar a troca de saberes entre professores com diferentes graus de experiências, o que inclui também os professores em formação. Assim, comunidades de prática são:

Comunidades intelectuais, sociais e organizacionais que dão suporte a aprendizagem de professores, promovendo oportunidades para que pensem, falem, leiam e escrevam sobre seus trabalhos diários, incluindo seus contextos sociais, culturais e políticos mais abrangentes, de maneira intencional e planejada (COCHRAN-SMITH; LYTLE, 2002, p. 2463). ${ }^{5}$

\footnotetext{
${ }^{4} \mathrm{O}$ contato com Cochran-Smith ocorreu através dos estudos empreendidos no GEPED (Grupo de Estudos e Pesquisa sobre Didática e Formação de Professores da Faculdade de Educação da UFRJ). Seus textos ainda não foram publicados em português. Todas as falas da autora transcritas neste artigo são traduções livres.

5 “Communites are the intelectual, social, and organizational configurations that suppport teachers' ongoing professional growth by providing opportunites for teachers to think, talk, read, and write about their daily work, incluing its larger social, cultural, and political contexts in planned and intentional ways".
} 
Para Cohran-Smith (2012), "deprivatization of practice" é um processo que permite o desenvolvimento de conhecimentos sobre a docência quando acompanhado de investigação e problematização dos saberes e fazeres docentes em um sistema de colaboração com outros que também estejam engajados no esforço para tornar o seu trabalho público e aberto a críticas. Aqui, entendemos como uma estratégia de formação docente que se desenvolve em espaços onde grupos com professores em diferentes níveis de formação e de experiência constroem conhecimentos sobre a docência a partir da problematização e da investigação sistemática de seus próprios saberes e fazeres que são compartilhados, registrados e analisados pelo grupo de modo intencional (planejado e organizado). Sendo assim, é uma ferramenta virtuosa por que se vale de mutualidade e reciprocidade, já que os professores, seja em formação inicial ou continuada, se desenvolvem profissionalmente enquanto contribuem no desenvolvimento de seus pares.

Passados dez anos desde sua implementação, o PIBID vive hoje um momento de grande fragilidade. Se em 2012 o Edital 11 tratava dos marcos legais ${ }^{6}$ do PIBID que o alçaram a uma política pública em educação para a formação de professores, e em 2013 o Edital 68 evidenciava essa condição, inclusive com uma alteração na LDB - Lei de Diretrizes e Bases da Educação nacional n. 9.394/19967 (ocorrida em 2012), o afirmando mais uma vez como política pública e não política de governo, hoje o programa se encontra vulnerável em face de recorrentes cortes orçamentários feitos a partir de 2014. Ainda que o discurso oficial seja de estabilidade, na realidade a ausência de ofertas de novas bolsas representa uma ameaça à sua continuidade. Mesmo assim, o PIBID continuou desenvolvendo suas atividades com as bolsas garantidas pelo Edital de 2013, com previsão de encerramento em fevereiro de 2018. Este trabalho soma-se aqueles que traduzem o esforço dos pesquisadores em educação de compor um quadro que expresse em dados empíricos as implicações, contribuições e influências do PIBID no cenário da formação docente brasileira (GATTI, 2013; ANDRÉ et al., 2014; AMBROSETTI et al. 2015;).

\section{Aspectos teóricos e metodológicos}

\section{Sobre a "desprivatização da prática"}

${ }^{6}$ A Lei ${ }^{\circ}$ 12.465, de 12 de agosto de 2011, o Decreto ${ }^{\circ} 7.219$, de 24 de junho de 2010 e as Normas Gerais do PIBID, aprovadas pela Portaria CAPES n 260, de 30 de dezembro de 2010.

${ }^{7}$ Referente ao Título VI - Dos Profissionais da Educação, Art. 62, Parágrafo $5^{\circ}$. 
Uma vez que a ideia de "deprivatization of practice” é central neste trabalho, torna-se importante explicitar aqui alguns pontos para a sua compreensão.

Como já mencionado, este termo é considerado por Cochran-Smith para caracterizar uma estratégia de formação docente que se desenvolve no seio de comunidades de professores que se reúnem no intuito de aprender a docência coletivamente. A autora trata diretamente sobre o tema em um texto de 2012. No entanto, verifica-se que a ideia está presente em diversas outras obras ${ }^{8}$ (COCHRAN-SMITH, 1993, 1999, 2002, 2005, 2009), permeando a sua argumentação a favor de uma formação de professores que emerge da prática profissional.

Desse modo, o estudo empreendido buscou mapear todas as falas de Cochran-Smith que incluíam o termo, no sentido de construir uma descrição conceitual, uma espécie de descritores. Isso se deu através de um processo que envolveu muitas leituras e partiu da seleção de extratos do texto de 2012 mais propícios ao entendimento do conceito. Estes extratos foram arrumados em quadros, aos quais foram sendo acrescentados extratos dos outros textos selecionados após análise (comparação em buscas de semelhanças e diferenças) por indicarem outros aspectos sobre o tema. Esses quadros foram lidos, relidos e rearrumados para que por fim, a partir do que a própria autora defende em seus trabalhos, fosse possível ver mais claramente o que é próprio do processo de "deprivatization of practice".

Assim, é possível conceituar "deprivatization of practice" como sendo uma estratégia formativa que permite a investigação e a problematização sobre e a partir do trabalho docente, e que envolve um conjunto de pressupostos sobre a aprendizagem da docência, tais como:

i) O professor é um construtor de conhecimento docente;

ii) A docência é um trabalho coletivo;

iii) Os saberes docentes são mais bem adquiridos/desenvolvidos quando os professores têm oportunidade de discutir o que fazem (porque, como) com outros que também o fazem.

A ideia de "deprivatization of practice" é motivada entre aqueles que a mobilizam pelas crenças compartilhadas de que todo aluno pode aprender, todo professor pode ensinar e de que a aprendizagem da docência está relacionada a processos coletivos de investigação e a problematização sobre e a partir do trabalho docente. Assim, tem como objetivo a busca intencional em promover aprendizagem docente e desenvolvimento profissional. Sua experimentação requer uma organização especial (ainda que não necessariamente física) e o envolvimento de professores de diferentes níveis e modalidades engajados e comprometidos

${ }^{8}$ Estas obras foram desenvolvidas em parceria com outros autores. 
com o processo. "Deprivatization of practice" envolve ações de documentação do que se faz, submissão à crítica do que se faz - com quem faz também - de maneira intencional, planejada e organizada (não é por acaso, não é ocasional) para melhorar e desenvolver o que faz. Quanto a essas ações, são caracterizadores os registros/relatos orais e escritos das práticas desenvolvidas pelos professores e a apreciação crítica coletiva desses registros/relatos.

Quadro 1 - Descritores de "deprivatization of practice"

\begin{tabular}{|l|l|}
\hline PRESSUPOSTOS & $\begin{array}{l}\text { 1) O professor como um construtor de conhecimento sobre a docência; } \\
\text { 2) A docência como um trabalho coletivo; } \\
\text { 3) A docência como um conhecimento que é adquirido/desenvolvido quando os } \\
\text { professores têm oportunidade de discutir o que fazem (porque, como) com outros } \\
\text { que também o fazem. }\end{array}$ \\
\hline MOTIVAÇÃO & $\begin{array}{l}\text { 1) Crença compartilhada de que todo aluno pode aprender e todo professor pode } \\
\text { ensinar. } \\
\text { 2) Crença compartilhada de que a aprendizagem da docência está relacionada a } \\
\text { processos coletivos de investigação e a problematização sobre e a partir do } \\
\text { trabalho docente. }\end{array}$ \\
\hline OBJETIVO & $\begin{array}{l}\text { Busca intencional de promover aprendizagem docente e desenvolvimento } \\
\text { profissional }\end{array}$ \\
\hline $\begin{array}{l}\text { EM QUE CONDIÇÕES } \\
\text { OCORRE? }\end{array}$ & $\begin{array}{l}\text { Requer uma organização especial (ainda que não necessariamente física) } \\
\text { QUEM PARTICIPA? }\end{array}$ \\
\hline $\begin{array}{l}\text { Envolvimento de professores de diferentes níveis e modalidades engajados e } \\
\text { comprometidos com o processo. }\end{array}$ \\
CARACTERIZAM? & $\begin{array}{l}\text { 1) Registro/relato oral e escrito das práticas desenvolvidas (intencional e } \\
\text { planejado) } \\
\text { 2) Apreciação crítica coletiva (problematizar, questionar, interrogar, comparar) } \\
\text { dos registros/relatos das práticas desenvolvidas }\end{array}$ \\
\hline
\end{tabular}

Fonte: Elaboração própria a partir da obra de Cochran-Smith.

É com base nesses descritores (definição, pressupostos, motivação, objetivo, organização, participantes e ações caracterizadoras) que foi desenvolvida a pesquisa em relato.

\section{Sobre os procedimentos metodológicos da pesquisa}

Com o propósito de investigar como se desenvolve a aprendizagem da docência no âmbito de subprojetos de Pedagogia de PIBIDs de Universidades públicas localizadas no estado do Rio de Janeiro, cuja ênfase recaísse sobre a etapa inicial do ensino fundamental, no sentido de localizar propostas com indícios de "deprivatization of practice", consideramos como primeiro passo metodológico mapear as instituições e seus referidos programas, procedendo-se, desse modo, levantamento no site da CAPES.

Cumpre esclarecer que a delimitação em torno da Pedagogia se justifica porque corresponde à formação inicial das autoras e porque representa curso de licenciatura com 
recorrentes contestações em relação à sua efetividade na formação de professores para a Educação Infantil e os anos iniciais do Ensino Fundamental, dada a abrangência e variação de ênfases de seu curso (CRUZ, 2011; CRUZ e AROSA, 2014).

O levantamento no site da CAPES, mais especificamente no relatório de pagamento de bolsas referente a dezembro de 2016, registrou a presença de 34 subprojetos PIBIDs Pedagogia no estado do Rio de Janeiro, distribuídos entre 12 IES, sendo sete delas públicas e cinco privadas. Somam-se no total 34 coordenadores de área, 85 professores supervisores e 481 licenciandos bolsistas.

Dois critérios, considerados essenciais, foram balizadores para a seleção dos subprojetos participantes do estudo: pertencer à universidade pública e destinar-se aos anos iniciais do ensino fundamental. O relatório de pagamento de bolsas da CAPES, documento oficial analisado, fornecia identificação da universidade, do curso, do coordenador institucional, dos coordenadores de área, dos supervisores e dos licenciandos bolsistas, não sendo possível depreender a ênfase do subprojeto.

Não tendo então pistas sobre a área de atuação dos programas, direcionamos a coleta de informações para os sites oficiais das universidades, e dos PIBIDs em questão, além de contato via e-mail com os coordenadores institucionais e de área. Desse modo, para identificar do conjunto de 34 subprojetos aqueles que atendiam aos requisitos de participação, passamos ao segundo passo metodológico: busca de informações sobre cada projeto nos sites oficiais das instituições e através de contato com os coordenadores institucionais e de áreas.

Dessa segunda busca, notou-se a prevalência de subprojetos envolvidos com os anos iniciais do ensino fundamental (10 recorrências), seguido de educação infantil (6 recorrências), observando, no entanto, a multiplicidade de possibilidades de atuação do PIBID Pedagogia no contexto estado do Rio de Janeiro, tendo em vista a identificação de subprojetos trabalhando com educação do campo (5), educação escolar indígena, educação especial, ensino médio e educação de jovens e adultos (1 indicação cada).

Por meio dessas estratégias, chegamos a nove subprojetos PIBIDs Pedagogia de cinco universidades, que desenvolvem atividades exclusivamente nos anos iniciais do Ensino Fundamental, perfazendo um total de 154 bolsistas de iniciação à docência, considerados sujeitos potenciais deste estudo. As IES mapeadas foram: UFRJ, FFP/UERJ, UFF campus Niterói, UFF campus Angra dos Reis, UFRRJ campus Seropédica e UNIRIO campus Urca.

No intuito de analisar o processo de aprendizagem da docência no âmbito dos PIBIDs identificados, optamos pela aplicação de questionário exploratório aos bolsistas em exercício de iniciação à docência. A opção pelo questionário se justifica em face do número de sujeitos 
envolvidos (154). O trabalho com esse instrumento representou, assim, o terceiro passo metodológico.

O questionário exploratório foi desenvolvido na ferramenta "Formulários Google", tendo sido composto de 14 questões, todas obrigatórias, divididas em dois blocos. As cinco primeiras questões - todas de múltipla escolha - compõem o bloco dados sócio etários e versam sobre idade, escolaridade anterior, entrada no curso de Pedagogia e sobre a realização (se houve) de estágios curriculares. O segundo bloco, sobre sua participação no PIBID, composto por oito questões - duas de múltipla escolha e seis discursivas - se refere à caracterização do PIBID ${ }^{9}$, do nível de segmento e modalidade em que atua o respondente e da caracterização da dinâmica do projeto em si, especialmente no que se refere ao relacionamento com o professor supervisor.

Quadro 6 - Quantitativo de sujeitos por universidade

\begin{tabular}{|l|c|c|}
\hline \multicolumn{1}{|c|}{ UNIVERSIDADE } & $\begin{array}{c}\text { QUANTIDADE DE } \\
\text { SUBPROJETOS EM ANOS } \\
\text { INICIAIS }\end{array}$ & $\begin{array}{c}\text { QUANTIDADE DE } \\
\text { LICENCIANDOS BOLSISTAS }\end{array}$ \\
\hline UFRJ & 01 & 16 \\
\hline FFPUERJ & 02 & 30 \\
\hline UFF Niterói & 02 & 40 \\
UFF Angra dos Reis & 02 & 21 \\
\hline UFRRJ Seropédica & 01 & 14 \\
\hline UNIRIO Urca & 01 & . \\
\hline
\end{tabular}

Fonte: Elaboração própria a partir das informações obtidas com coordenadores institucionais e de área ao longo dos meses de fevereiro e março de 2017.

O questionário ficou disponível para resposta por dois meses (de $1^{\circ}$ de abril até 31 de maio de 2017), tendo sido enviado aos licenciandos bolsistas através dos coordenadores institucionais e de área previamente contactados. Obteve-se um retorno de 35\%, atingindo um total de 50 respostas. Embora ciente dos limites que este quantitativo de respostas impõe para a análise, consideramos satisfatório o retorno, tendo em vista que não houve controle da aplicação do instrumento, no sentido do envio direto aos possíveis respondentes.

Após a aplicação do questionário exploratório e transcorrido o tempo estipulado para as respostas, passamos à análise dos dados com ele obtidos. $\mathrm{O}$ primeiro movimento foi o de verificar se de fato todos os respondentes estavam desenvolvendo atividades através do PIBID Pedagogia nos anos iniciais do Ensino Fundamental. Verificamos que não era o caso dos

${ }^{9} \mathrm{O}$ questionário é totalmente anônimo e não há informações inclusive sobre o e-mail dos respondentes, ainda que a ferramenta viabilize o envio das respostas online. 
respondentes de uma IES, posto que atuavam também em outras etapas da educação básica. Assim, foram considerados válidos para análise 38 questionários referentes a cinco IES.

Quanto à análise dos dados da segunda parte do questionário - foco do relato -, primeiro organizamos um quadro por IES com as respostas do questionário em subsequência. Em um segundo momento marcamos com cores iguais as respostas que de alguma forma se relacionavam. Isso foi feito por questão e por instituição. Feito isso, em uma espécie de "brain storm", redigimos tópicos descritivos sobre cada PIBID a partir do que os conjuntos de respostas semelhantes (identificados por cor) nos permitia ver. Na quarta fase da análise, fizemos um segundo quadro por instituição considerando os conjuntos de respostas semelhantes e os tópicos que construímos e os comparamos com os descritores de "deprivatization of practice" em busca de recorrências e divergências que foram sinalizadas com novas marcações por cor. Por fim, construímos um terceiro quadro com as semelhanças e diferenças com "deprivatization of practice" identificadas em cada instituição. Entre cada etapa da análise fez-se intervalos para leitura e releitura dos quadros até então produzidos.

Identificamos no PIBID da UFRRJ Seropédica e da UFRJ aspectos que se assemelham ao que Cochran-Smith (2012) caracteriza como "deprivatization of practice" em termos de ação estratégica formativa docente. Nos deteremos na análise desses fatores a partir dos dados construídos, levando em conta a segunda parte do questionário exploratório.

\section{Aprendizagem da docência no PIBID Pedagogia: o que dizem os licenciandos bolsistas da UFRJ e da UFRRJ seropédica}

Do grupo de respondentes, oito são licenciandos bolsistas do PIBID da UFRJ e dez do PIBID da UFRRJ. Tendo em vista os descritores da desprivatização da prática, a saber: i) busca intencional de promover aprendizagem docente e desenvolvimento profissional; ii) envolvimento de professores em diferentes níveis de formação engajados e comprometidos com o processo; iii) ações de documentação do que se faz e de submissão à crítica do que se faz com quem também faz de maneira intencional, planejada e organizada; nos deteremos na descrição desses aspectos identificados nos PIBID em questão.

Quanto à busca intencional de promover aprendizagem docente e desenvolvimento profissional, foi possível depreender que os encontros do PIBID UFRRJ são voltados para o planejamento das atividades e avaliação das mesmas, mas existem também momentos de estudo e de preparação de trabalhos "acadêmicos". Existem encontros semanais específicos dos pibidianos com seu supervisor e existem encontros mensais com todo o grupo. Um dos 
depoentes descreve os encontros do PIBID como "um espaço de diálogos, pesquisas, questionamentos e troca de conhecimento", outro declara que nas reuniões "os planejamentos são definidos, e após as atividades, são avaliadas as nossas práticas". Os extratos a seguir corroboram essa visão:

Discutimos questões sobre o Programa, metas alcançadas e as que ainda estão sendo galgadas, realizamos avaliações quinzenais. Essas reuniões ocorrem geralmente na Universidade, mensalmente, com a equipe completa de Pedagogia, ou seja, as 15 "pibidinhas", a coordenadora geral e as supervisoras da escola. Temos também reunião específica de cada grupo, semanais, onde discutem-se principalmente, o trabalho realizado da semana e o que podemos melhorar. Além de novas ideias e instruções passadas pela coordenadora e supervisora.

Os encontros são para planejar, como abordar o tema, posicionamento no espaço escolar, com as crianças e professores. Sim, temos reuniões para todo tipo de discussões, dúvidas, orientações e questionamentos. Os licenciandos trazem as demandas das escolas e das crianças, supervisores e coordenadores, auxílio para resolvê-las.

Quanto a esse aspecto, os depoimentos apontam que os encontros do PIBID da UFRJ são voltados para estudo, planejamento, avaliação das ações e discussão coletiva sobre a sala de aula (o observado e o vivido) a partir de registros. Prevalecem o falar e o ouvir. São realizadas também oficinas oferecidas por professores da escola básica. Um dos respondentes diz que os encontros do seu grupo "são muito importantes e construtivos na formação docente, é um grande espaço dialógico onde ouvimos e somos ouvidas pelos supervisores onde temos a possibilidade de uma aprendizagem na prática”. Outro menciona que "trocamos experiências e avaliamos cada ação promovida com o intuito de aperfeiçoamento".

Nos encontros semanais do PIBID discutimos sobre a entrada no campo, sobre os diários de campo de cada pibidiano (o que mais lhe chamou a atenção e por que, no sentido de que cada um desenvolva uma investigação mais apurada sobre o que mais lhe interessa), às vezes sobre uma determinada bibliografia selecionada para a reunião. Quando os pibidianos passam a de fato atuar em sala de aula, as reuniões são dedicadas a conversar sobre as intervenções: como foi o planejamento, a ação, o desenvolvimento, qual foi o balanço do(s) pibidiano(s) sobre o planejado e o ocorrido. Nesta situação o professor supervisor tem papel central, na medida em que ele(a) pode transparecer a visão de um observador 'profissional'.

Lemos livros de literatura infanto juvenil, poesias. Apresentamos propostas, dialogamos a respeito dos encaminhamentos de cada proposta. Analisamos o material de registro (cadernos de campo, memorial de formação, as 
gravações das atividades realizadas, portfólios). Temos o feedback dos planos de aula que foram encaminhados para as supervisoras.

Processos que envolvem "deprivatization of practice" pressupõem o reconhecimento dos professores "não apenas como recebedores de informação ou implementadores de métodos de ensino e currículo, mas também tradutores e intérpretes de um assunto, inventores de estratégias de ensino, e geradores de conhecimento, currículo e instrução" (COCHRANSMITH; LYTLE, 2002, p. 2461) ${ }^{10}$, o que legitima seu lugar na formação de seus pares.

Ao falarem desse trabalho coletivo em comunidades, Cochran-Smith e Lytle, (1999) afirmam que os professores apresentam problemas, identificam discrepâncias entre teorias e práticas, desafiam rotinas comuns, se baseiam no conhecimento de outros para construir novos conhecimentos, e tentam tornar visível muito do que é considerado dado no ensinoaprendizagem. A partir de uma postura de investigação, os professores buscam questões significativas à medida que se envolvem com a resolução de problemas. Contam com outros professores para obter pontos de vista alternativos sobre seu trabalho e assim se desenvolverem profissionalmente.

Quanto ao envolvimento de professores em diferentes níveis de formação engajados e comprometidos com o processo, foi possível perceber que o professor supervisor, na UFRRJ, participa de todo o processo, assim como o coordenador e os licenciandos, e parece ser o elo com a escola. Sobre o planejamento das atividades, o professor supervisor parece ter papel decisivo nele. As atividades são desenvolvidas através de projetos construídos coletivamente. Elas são planejadas e avaliadas dentro das reuniões e é o professor supervisor quem acompanha/coordena este processo. Notamos indícios que tanto professores em formação inicial, quanto aqueles que já exercem a docência - seja na escola básica, seja na universidade - atuam de forma equilibrada e não hierárquica no PIBID UFRRJ, tal como demonstram os extratos a seguir:

O planejamento é elaborado com todos nós, de cada grupo, baseado no tema proposto, e nele tentamos encaixar o nosso aprendizado com a real necessidade da escola e os alunos, visando uma práxis em que todos se ajudam mutuamente.

As atividades são planejadas entre os bolsistas com a supervisão da professora, são feitas discussões após todas as atividades planejadas mesmo aquelas que não foram cumpridas por algum motivo.

10 “[...] not just receivers of information or implementers of teaching methods and curriculum, but also translatorsand interpreters of subject matter, inventors of teaching strategies, and generators of knowledge, curriculum and instruction." 
Os respondentes da UFRJ deixam claro que o professor supervisor está presente em todas as ações que desenvolvem. Seja na orientação, no acompanhamento, na avaliação ou até mesmo na execução é possível perceber a coletividade por meio do diálogo. O planejamento das atividades é feito pelos licenciandos bolsistas e é alvo de discussão e crítica coletiva nos encontros do grupo, nos quais o compartilham com todos. Os planejamentos são feitos semanalmente e as ações em si são alvo de análise através dos registros em vídeo, que geram novos registros, que geram novas discussões.

O planejamento de atividades, de forma geral, é feito em duplas e trios (que atuam no mesmo dia e na mesma turma) e é compartilhado com o grupo elou com as professoras supervisora e coordenadora. As atividades são pensadas com base em demandas observadas em sala de aula. Atualmente cada dupla ou trio planeja e implementa as atividades cerca de duas vezes por mês em um "esquema de rodízio". Sobre o momento de avaliação, adotamos a estratégia de vídeo gravação, então depois que as atividades são realizadas os bolsistas que atuam na mesma escola parceira se reúnem para assistir o vídeo e em conjunto avaliar o que foi feito pensando na proposta de atividade, na postura do bolsista na "condução" da atividade, na forma de lidar com as crianças, etc. e propondo ações que poderiam ter sido diferentes. Em seguida, a dupla ou trio que planejou a atividade produz uma escrita reflexiva sobre o momento, considerando também a avaliação feita em grupo, e encaminha essa escrita para as professoras supervisora e coordenadora que dão uma devolutiva.

Ainda que o foco pareça estar no "professor experiente", os processos de "deprivatization of practice" se desenvolvem mediante o envolvimento de professores de diferentes níveis (inclusive em formação inicial) e modalidades engajados e comprometidos com o processo. Cochran-Smith (2012) sinaliza a importância do contexto de "grupo iniciado por professores, ensinado por professores e conduzido por professores de várias escolas, comprometidos com a educação urbana" (p. 7) ao descrever como uma professora compartilhava seus fazeres e saberes com: "candidatos a professores e seus auxiliares e muitos professores de outros grupos estabelecidos de professores" (COCHRAN-SMITH, 2012, p. 114) ${ }^{11}$.

Nesse sentido, tão importante quanto investigar ${ }^{12}$ a docência é investigar a docência coletivamente, entendendo que se aprende mais e melhor sobre o trabalho docente quando os professores expõem o que fazem dentro das salas de aula. Nessa perspectiva, a criação de

11 " [...] teacher candidates and their cooperating teachers, which were part of the program. And many teachers from TLC and other established teacher groups served as cooperating teachers and supervisors in Gill's preparation program."

12 Investigar aqui neste contexto não se relaciona necessariamente a pesquisa sistemática, no sentido de cientificidade e rigor acadêmico. Está muito mais próximo ao esforço coletivo (em pares) de responder a problemas intrínsecos à realidade do trabalho, pelo trabalho e para o trabalho. 
ambientes em que professores em formação inicial e professores já atuantes na escola básica possam pensar juntos sobre o trabalho docente é profícuo para aproximar universidade e escola com vistas a conectar conhecimentos acadêmicos e profissionais. Para Cochran-Smith e Lytle (2002), é imprescindível que se criem grupos sociais de professores em formação, iniciantes e experientes que se juntem com o tempo, pelo propósito de obter novas informações, reconsiderar crenças e conhecimentos prévios e construir suas próprias ideias e experiências, assim como de outros, a fim de trabalhar com uma intenção específica de melhorar a prática e a aprendizagem de estudantes em escolas.

Especificamente quanto a indícios de engajamento com o processo, os depoimentos mostram que o professor supervisor da UFRRJ acompanha o trabalho dos licenciandos bolsistas, coordenando e monitorando o planejamento das atividades. Participa da execução das atividades planejadas e conversa sobre elas com os licenciandos; nessas conversas de planejamento e de avaliação, fala do seu trabalho, fala da sua prática, aceita críticas e sugestões. Aparentemente, os licenciandos não assistem as aulas dos professores supervisores, mas as conhecem pelos relatos deles - os licenciandos falam e escutam sobre a sala de aula, como se poderá notar a seguir:

Ocorre uma relação de aprendizado bastante satisfatória, pois na UFRRJ, somos tratadas com muito amor e carinho, além disso, somos respeitadas como futuras professoras, ou seja, o trabalho é gratificante. Tanto as coordenadoras da Rural, quanto as supervisoras da escola onde realizamos o trabalho, nos instruem, nos ajudam e nos dão autonomia de criarmos e montarmos nossas aulas. Sugerem, e recebem nossas sugestões. Registramos tudo por fotos, e relatamos por via oral e por notificações pela rede social (Facebook). Cada grupo [...] com seu coordenador, relata as atividades semanalmente.

Ele [professor supervisor] sempre está na sala de aula conosco, dependendo da atividade ele participa, e eventualmente ele conversa com os bolsistas sobre determinados acontecimentos no decorrer das atividades [...]. Ele conversa conosco sobre suas atitudes e também temos oportunidade de conversar com ele sobre isso.

Ainda no que se refere ao engajamento com o processo, os depoimentos da UFRJ descrevem uma relação "aberta e de diálogo" entre os membros do grupo e especialmente entre os licenciandos bolsistas e os professores supervisores. Os respondentes mencionam conversas sobre o que os supervisores fazem na sala de aula tanto quanto sobre o que os licenciandos mesmos fazem. Os professores expõem as razões de por que ensinam como ensinam e estão abertos a críticas, falam do seu planejamento para além do que concerne ao PIBID e pedem avaliações sobre seu trabalho. Os supervisores priorizam conversas coletivas 
em que participam vários licenciandos. Foi possível perceber com os relatos que a força motriz dessa relação é o ensino.

Logo nos primeiros encontros conversamos sobre as razões pelas quais ambos escolhemos ser professores. A supervisora sempre nos conta sobre seu planejamento diário e o que ocorreu durante a semana após as nossas atividades e dá ideia para novos encaminhamentos. Nos pergunta com frequência o que achamos de sua aula, dos encaminhamentos dados. Assiste as gravações e nos ajuda a colocar as propostas em prática.

A professora supervisora sempre comenta sobre as suas atitudes na sala de aula e explica o porquê fez de uma forma e não de outra. Nos momentos em que tive dúvidas sobre alguma coisa relacionada a alguma ação minha ou até mesmo de algo que envolva a turma ela sempre me respondeu e orientou.

"Deprivatization of practice" requer uma organização especial (ainda que não necessariamente física), tal como o evidencia Cochran-Smith (2012) sobre a experiência de uma professora:

No que ela chamou "um ato de desespero", Gill começou a frequentar a "Cooperativa de Ensino de Professores", a TLC (Teachers Learning Cooperative) o que acabou sendo uma encruzilhada para ela em termos de 'desprivatização da sua prática' (embora ela não tenha usado essa palavraconceito) (COCHRAN-SMITH, 2012, p. 113) ${ }^{13}$.

Esse processo vai além de trocar experiências com outros professores. Isso é muito importante, mas não é suficiente. No sentido de ter contato com professores experientes que compartilham o que fazem, não significa replicar e copiar coisas simplesmente porque outros já o fizeram com sucesso - não é para aprender "técnicas" -, mas para aprender sobre o processo intelectual (escolhas racionais, teórico-empíricas) que levam o professor a adotar uma estratégia e não outra.

Felizmente para Gill, havia um professor experiente que a colocou sob suas asas, advogou por ela em diversas questões com diretora, e a defendeu como colega de profissão. Havia alguns companheiros que ensinavam nos mesmos níveis em que Gill ensinava, que foram generosos em compartilhar materiais e ideias. De qualquer maneira, ela comentou que, cada vez mais, ao longo de seu primeiro ano, ela se sentia simplesmente uma "professora ruim". (COCHRAN-SMITH, 2012, p. 113) $)^{14}$

13 "In what she called an act of "desperation," Gill began to attend the Teachers Learning Cooperative (TLC), which turned out to be a crossroads for her in terms of deprivatizing her practice (though she did not use that word or concept)".

14 "Fortunately for Gill, there was an experienced teacher who took her under her wing, advocated for her in several issues with the principal, and defended her as a professional colleague. And there were grade-level 
Desesperada por soluções, Gill comentou que ela tentava constantemente qualquer coisa que visse qualquer pessoa fazendo, o que não era apenas exaustivo, mas também não era algo honesto com si própria. (COCHRANSMITH, 2012, p. 113) $)^{15}$

Quanto às ações de documentação do que se faz e de submissão à crítica do que se faz com quem também faz de maneira intencional, planejada e organizada, os depoimentos da UFRRJ revelam que prevalecem o registro em fotos e vídeos (7 indicações), seguido por registro escrito em grupo de licenciandos bolsistas (6 indicações). Notam-se atividades de registro desenvolvidas com o supervisor, sejam escritas (5 indicações) ou orais (4 indicações). Também são indicados registros orais de grupos de pibidianos (3), registros orais individuais dos pibidianos (2) e registros escritos individuais dos pibidianos (2). A dinâmica das ações de planejamento - ação - avaliação - replanejamento descritas nas questões sobre os encontros e sobre o próprio planejamento dá indícios de que os registros são intencionais e tornados estratégias de aprendizagem pela crítica e pela reflexão de modo constante, uma vez que a indicação que prevalece é de que os registros são feitos semanalmente (6).

Nesse quesito, os depoimentos deixam ver que os registros têm papel central na organização do PIBID da UFRJ. São mencionados momentos de registro do que se fez e registros a partir destes, parecendo claro que as documentações têm lugar também para reflexão, acompanhamento e avaliação. A dinâmica dos encontros do grupo revelada pelos depoentes deixa ver que os relatos são alvo de crítica e não um fim em si mesmos, mas ponto de partida para problematização e construção de novos conhecimentos pela análise coletiva não hierárquica. Quanto ao tipo de registros, prevalecem os escritos individuais e os em fotos e vídeos (8 indicações cada). Em seguida registros escritos em grupos de licenciandos bolsistas (7 indicações), registro oral individual e registro oral em grupos de licenciandos bolsistas (4 indicações cada). São mencionados também registros escritos e orais em grupos de licenciandos bolsistas com o professor supervisor (2 indicações cada). Todos os licenciandos bolsistas mencionam que os registros são feitos e levados ao escrutínio do grupo semanalmente.

Ora, "deprivatization of practice" caracteriza-se pelas ações específicas de documentar o que se faz e submeter à crítica o que se faz. Tudo isto de maneira intencional, planejada e

partners who were generous in sharing materials and ideas. Nonetheless, she reported that, increasingly during her first year, she felt she was just "bad at teaching."

15 "Frantic for solutions, Gill reported, she was constantly trying everything she saw anyone else doing, which was not only exhausting, but also not true to herself." 
organizada para melhorar e desenvolver o que faz, na companhia de quem o faz também. Cochran-Smith especifica isso ao falar do grupo do qual a professora Gill participava:

Os escritos dos membros do TLC e de outros grupos de professores, e escritos individuais de outros professores, eram incluídos como parte de leitura na bibliografia dos cursos [...] professores do TLC e de outros grupos de professores faziam apresentações sobre seus trabalhos (COCHRANSMITH, 2012, p. 114) ${ }^{16}$.

Dessa maneira, segundo Cochran-Smith (2002 e 2012), este processo promove oportunidades para que professores pensem, falem, leiam e escrevam sobre seus trabalhos diários, incluindo seus contextos sociais, culturais e políticos mais abrangentes, de maneira intencional e planejada. Ao problematizar, questionar, interrogar, comparar os registros/relatos das práticas desenvolvidas, os professores constroem conjuntamente conhecimento sobre a docência quando refletem criticamente e trabalham com outros a cultura de suas escolas: "o trabalho dos professores melhora quando eles têm oportunidade de documentá-lo e criticá-lo com outros professores, de maneira estruturada" (COCHRANSMITH, 2012, p. 113) ${ }^{17}$.

\section{Considerações finais}

O estudo desenvolvido permitiu identificar tanto no PIBID Pedagogia da UFRJ quanto no da UFRRJ Seropédica indícios da mobilização de "deprivatization of practice" como estratégia de formação de professores porque há uma busca intencional de promover aprendizagem docente e desenvolvimento profissional; há o envolvimento de professores em diferentes níveis de formação - supervisores e licenciandos trabalham coletivamente de modo contínuo - engajados e comprometidos no processo; e há ações de documentação do que se faz e de submissão à crítica do que se faz com quem também faz de maneira intencional, planejada e organizada.

Reconhecemos que em um universo de oito subprojetos de Pedagogia, apenas dois tenham apresentando características com verossimilhança com processos de "deprivatization of practice". Cumpre esclarecer que dos oito subprojetos analisados cinco atendiam a pelo menos dois dos critérios elencados a partir de Cochran-Smith (2012) enquanto um deles não

16 “ $[\ldots]$ the writings of TLC members and other teacher groups and individuals were included as part of the reading on course syllabi. In addition, teachers from TLC and other teacher groups made presentations about their work."

17 "[...] that teachers' work improves when they have opportunities to document it and critique it with other teachers in structured ways." 
revelara nenhum. Optamos por relatar aqui aqueles que atendiam a todos os três descritores. Salientamos que esta aproximação se fez pela lente escolhida para analisar os dados, não havendo indícios de que os PIBIDs investigados desenvolvam ações pautadas intencionalmente em processos de "deprivatization of practice".

Apostamos na potencialidade dessa estratégia de formação docente, uma vez que possibilita a construção de conhecimento sobre a docência a partir do compartilhamento, análise, problematização e investigação por parte dos professores dos seus próprios saberes e fazeres, em um sistema de colaboração com outros que também estejam engajados no esforço para tornar o seu trabalho público e aberto a críticas. Porque o saber docente se constrói na mobilização, na interrogação, no questionar e no comparar; se amplia e se solidifica quando é comunicado e discutido, uma vez que advém da teorização sobre a ação; buscamos defender que deprivatization of practice é uma estratégia de formação docente potente para desenvolvê-lo.

Consideramos que o PIBID, por se basear em uma imersão orientada na escola, que possibilita aos licenciandos construir conhecimentos sobre a docência em experiências mediadas tanto por professores da universidade quanto por professores da escola básica, favorece a interligação, através da investigação e da reflexão, de conhecimentos acadêmicos e práticos. Identificamos que nesses arranjos há meio favorável para "deprivatization of practice" e há fortes indícios de que ela de fato ocorra, como tem sido apontado em outros trabalhos (CAMPELO; CRUZ, 2016a, 2016b, 2017a, e 2017b).

Esperamos contribuir apontando caminhos para a formação inicial docente com base no pressuposto da potencialidade de espaços onde professores da escola básica compartilham suas práticas e fazem dela objeto de problematização e investigação, viabilizando a oportunidade de reflexão sobre os fazeres e saberes que constituem o trabalho docente a partir do investimento nele próprio - "deprivatization of practice".

\section{REFERÊNCIAS}

AMBROSETTI, N. B. et al. O PIBID e a aproximação entre universidade e escola: implicações na formação profissional dos professores. Atos de Pesquisa em Educação. Blumenau, v. 10, n. 2, p. 369-392, maio/ago., 2015.

ANDRÉ, M. E. D. A. et al.; colaboradores. Relatório Final de Pesquisa. CNPq, 2014.

CAPES/FORMAÇÃO DE PROFESSORES DA ESCOLA. BÁSICA - PIBID. Disponível em: www.capes.gov.br/educacao-basica/capespibid. Acesso em: 10 mar. 2018. 
BRASIL. Decreto n. 6.755, de 29 de janeiro de 2009. Institui a Política Nacional de Formação de Profissionais do Magistério da Educação Básica, disciplina a atuação da Coordenação de Aperfeiçoamento de Pessoal de Nível Superior - CAPES no fomento a programas de formação inicial e continuada, e dá outras providências. Diário Oficial da União, Brasília, DF, 30 jan. 2009.

CAMPELO, T. da S. A atuação de professores supervisores do PIBID na formação de pedagogos docentes: diferenciais da parceria universidade - escola básica. $2016.129 \mathrm{f}$. Dissertação (Mestrado em Educação) - Universidade Federal do Rio de Janeiro, Rio de Janeiro, 2016a.

CAMPELO, T. da S.; CRUZ, G. B. Parceria universidade-escola básica e a aprendizagem da docência: contribuições da relação entre os professores supervisores do PIBID e os licenciandos bolsistas. RBPFP - Formação Docente, Belo Horizonte, v. 09, n. 15, p. 95-108, ago./dez,. 2016b.

CAMPELO, T. da S.; CRUZ, G. B. O PIBID e a aprendizagem da docência: a intervenção do professor supervisor. Crítica Educativa (Sorocaba/SP), v. 3, n. 2 - Especial, p. 188-203, jan./jun., 2017a.

CAMPELO, T. da S. Escola e formação de professores: investigação e problematização sobre o trabalho docente no PIBID. e-Mosaicos. v. 6, n.11, abr., $2017 \mathrm{~b}$.

COCHRAN-SMITH, M. A tale of two teachers: Learning of teach over time. In: Kappa Delta pi Record, july-sept, 2012. Tradução: GEPED (Grupo de Estudos e Pesquisas em Didática e Formação de Professores), 2012. p. 108-122.

COCHRAN-SMITH, M.; LYTLE, S. Inside/outside: Teacher research and knowledge. New York: Teachers College Press, 1993. Tradução: GEPED (Grupo de Estudos e Pesquisas em Didática e Formação de Professores).

COCHRAN-SMITH, M.; LYTLE, S. Relationships of knowledge and practice: teacher learning in communities. In: IRAN-NEJAD, A.; PEARSON, P. D. Review of research in education, v. 24, n. 1, p. 249-305, 1999.

COCHRAN-SMITH, M.; LYTLE, S. Teacher Learning Communities. Encyclopedia of Education. 2nd Edition. J. Guthrie (eds.). New York: Macmillan, 2002. Tradução: GEPED (Grupo de Estudos e Pesquisas em Didática e Formação de Professores).

COCHRAN-SMITH, M.; FRIES, K. Researching teacher education in changing times: politics and paradigms. In: COCHRAN-SMITH, M.; ZEICHNER, K. Studyin Teacher Education, 2005. Washington, DC: American Educational Research Association. Tradução: GEPED (Grupo de Estudos e Pesquisas em Didática e Formação de Professores). p. 69-105.

COCHRAN-SMITH, M.; LYTLE, S. Inquiry as stance: practitioner research for the next generation. New York: Teachers College Press, 2009. Tradução: GEPED (Grupo de Estudos e Pesquisas em Didática e Formação de Professores).

CRUZ, G. B. da. Curso de Pedagogia no Brasil: história e formação com pedagogos pimordiais. Rio de Janeiro: WAK, 2011. 
CRUZ, G. B. da.; AROSA, A. C. C. A formação do pedagogo docente no curso de Pedagogia. Revista Educação e Cultura Contemporânea, v. 11, n. 26, p. 30-68, 2014.

FUNDAÇÃO CARLOS CHAGAS. Um estudo avaliativo do Programa Institucional de Bolsa de Iniciação à Docência (Pibid). Bernardete A. Gatti; Marli E. D. A. André; Nelson A. S. Gimenes; Laurizete Ferragut, pesquisadores. São Paulo: FCC/SEP, 2014.

GATTI, B. A. Educação, escola e formação de professores: políticas e impasses. Educar em Revista, Curitiba, Brasil, n. 50, p. 51-67, out./dez. 2013.

\section{Como referenciar este artigo}

CAMPELO, T. da S.; CRUZ, G. B. da. "Deprivatization of practice" como estratégica de formação inicial docente no PIBID Pedagogia. Revista Ibero-Americana de Estudos em Educação, Araraquara, v. 14, n. 1, p. 169-187, jan./mar., 2019. E-ISSN: 1982-5587. DOI: 10.21723/riaee.v14i1.11045

Submissão: 14/02/2018

Revisões requeridas: 30/05/2018

Aprovação final: 20/09/2018 